\title{
Adipokine expression and endothelial function in subclinical hypothyroidism rats
}

\author{
Ningning Gong ${ }^{1,2, *}$, Cuixia Gao ${ }^{3, *}$, Xuedi Chen', Yu Wang' and Limin Tian \\ 1Department of Endocrinology, Gansu Provincial Hospital, Lanzhou, China \\ ${ }^{2}$ Department of Clinical Medicine, Gansu University of Chinese Medicine, Lanzhou, Gansu, China \\ ${ }^{3}$ Department of Ultrasonic Diagnosis, Gansu Provincial Hospital, Lanzhou, China \\ Correspondence should be addressed to L Tian: tIm6666@sina.com \\ *(N Gong and C Gao contributed equally to this work)
}

The authors and journal apologise for an error in the above paper, which appeared in volume 7 part 2, pages $295-304$. The error relates to the text in the 'Animal model' section of the 'Materials and methods' section given on page 296:

The original article stated:

'In the sHT rats, groups A-C were separately induced by administration of $20 \mathrm{mg} / \mathrm{kg} / \mathrm{day}$ methimazole (MMI), $30 \mathrm{mg} / \mathrm{kg} /$ day MMI and $40 \mathrm{mg} / \mathrm{kg} /$ day MMI once daily by gavage.'

This should have stated:

'In the sHT rats, groups A-C were separately induced by administration of $5 \mathrm{mg} / \mathrm{kg} / \mathrm{day}$ methimazole (MMI), $15 \mathrm{mg} / \mathrm{kg} /$ day MMI and $20 \mathrm{mg} / \mathrm{kg} /$ day MMI once daily by gavage.'

http://www.endocrineconnections.org https://doi.org/10.1530/EC-18-0007e
C) 2018 The authors Published by Bioscientifica Ltd

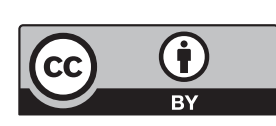

This work is licensed under a Creative Commons Attribution 4.0 International License. 